\title{
Demand-oriented Competency Development in a Manufacturing Context: The Relevance of Process and Knowledge Modeling
}

\author{
Gergana Vladova \\ University of Potsdam \\ gvladova@1swi.de
}

\author{
André Ullrich \\ University of Potsdam \\ aullrich@1swi.de
}

\author{
Eldar Sultanow \\ Capgemini \\ eldar.sultanow@capgemini.com
}

\begin{abstract}
Competency management is a crucial success factor for organizations in the area of tension between knowledge management, human resource management, and process management, and has to be considered from a knowledge economy perspective. A basis for developing appropriate qualification measures in organizations is the comparison of necessary and available competencies. Given the time and cost intensity of the comparison process, the use of appropriate methods is of particular relevance for enterprises. This paper presents a procedural method and a software tool which enable resource-saving comparisons. Usually, employees" "to competencies" are determined on a strategic level. Currently available "is competencies" can be derived from the actual knowledge transfer or from existing competence profiles. The method and tool first allow for the appropriate visualization of both competencies. After an automatized comparison of both contents, an overview of given and missing "to competencies" will be provided. Not available competencies can be addressed as qualification requirements and reflections regarding staffing or task allocation can be conducted.
\end{abstract}

\section{Introduction}

Knowledge economics is a field of rising interest in the area of knowledge management [32] throughout developed, transition, emerging, and developing countries [40] and deals with the financial impact of knowledge creation, modification, distribution and use [31]. This economical consideration of knowledge management also penetrates related disciplines such as competence management [33], human resource management [34, 35], or process management [38]. Especially, the financial aspects of the identification, acquisition, creation, preservation, or distribution of competences are just like non-negligible [36] as the creation and usage of auxiliary materials such as qualification matrices, staffing algorithms, or competency profiles. On the other hand, an efficient handling of employees, their knowledge and their competencies leads to potential financial benefits [32] based on increasing the efficiency, effectiveness, or value of processes, services, or products. Hence, the organizational usage of such auxiliary material seems beneficial, if properly applied and executed.

Defining and describing competency profiles is a long and effortful process that requires careful study of the employees, their specific tasks, and the respective organization [1]. This yet laboriously effort doesn't directly lead to instant and measurable improvements in well functioning organizational processes [29] or directly creates an economic value contribution [30]. Especially small and medium-sized enterprises (SME's) lack in understanding of its benefits and necessity as well as, more decisively, often in capacities for such strategic decisions [27]. Thus, they usually imitate high-profile companies [28], even if competency management is highly dependent from various specific external and internal organizational factors [27]. Furthermore, the outcome can mostly be recognized in the long term. These are the reasons why many organizations are often not willing to allocate significant resources to competency management and do not develop and use competency models. However, there are many persuasive arguments for implementing and using competency models. In particular, in industrial environment where work organization concepts such as job enlargement, job enrichment, or job rotation constitute a mandatory part of competency and personal development as well as ensure necessary redundancies in case of staff shortages, it is essential to know which employee possesses which competencies and how these are aggregated [37].

Process changes often cause task changes for the involved employees which lead to new required competencies. For gaining an overview of the current competency state and to identify necessary actions, a 
comparison of is competencies and to competencies is indispensable. However, there are almost no free accessible tools for such a comparison available [2]. Up to now, there is no open platform for knowledge and process management available, which provides professional skill management and staffing functions. This deficiency motivates the further development of the Modelangelo tool presented here. Modelangelo is a modeling and analysis tool, which allows different views on a process and the modeling of knowledge flows and conversions, validates the syntactic correctness of the models, detects process improvement possibilities through the search of predefined patterns and generates reports [24]. On the basis of two existing reports - the competence report which visualizes all available knowledge objects as well as the task coverage report which visualizes all persons fulfilling a specific task, new functions have been integrated in order to enable users to easily and economically apply the method presented here.

In the tool, the engine for competency and skill searching is based on XQuery 3.0 Standard (https://www.w3.org/TR/xquery-30/) and uses the powerful Saxon Library (http://saxon.sourceforge.net/). The search queries are defined and managed in separate xqy-files. Modelangelo traverses any given xml file containing KMDL models and distills the candidates (knowledge holders) that match project requirements. Such an open configurative and extensive method has so far not been provided by any other tool.

The paper focuses on employee competencies with an emphasis on change processes and aims to present 1) a procedural model for the context-sensitive identification and development of competencies and 2) a supporting software tool for resource-saving and efficient comparison of is- and to-competencies. This practical and relevant topic has been analyzed through the example of the transformation of existing factories into Industry 4.0 compliant factories. The metamorphosis of these enterprises is both extremely cost and time intensive as well as linked to various uncertainties and risks: Given the visionary character of the process, there is a lack of theoretical background and practical evidence, and the appropriate methods and concepts will be simultaneously both developed and applied. For this purpose, the research work was designed as action research.

The paper is organized as follows. Section 1 puts the problem in concrete terms, specifies the object of investigation and explicates the relation of knowledge economics, competency management, and human resource management. Section 2 describes some general specifics of competency management with an emphasis on the strategic importance of this management aspect, introduces some generals about cyber-physical systems, and emphasizes on the importance of competencies in manufacturing context. Section 3 illustrates the investigation focus, specifies the main questions and the research design, and points out the usefulness of knowledge modeling. Within this, the software tool will be introduced. Section 4 introduces the procedural model and depicts some results on behalf of an application example. The conclusions are exemplified in Section 6.

\section{Competency identification and development in a manufacturing Industry 4.0 context}

The aim of the modeling and analyzing method described in this paper is to simplify the process of competency profile generation as well as the comparison of target-performance profiles. The results will build the base for customized staffing and qualification processes of an organization. Specific object of investigation are Industry 4.0 relevant transformation processes of manufactories. Generally speaking, these transformations are characterized by parallel changes in processes and tasks. Especially the shifting in tasks for the different activity types towards supervision and rotation between diverse workstations and processes represent employee relevant changes [3]. The practical implications come from the operations of three globally operating corporations in the fields of semiconductor industry, automation technology, and transformer technology.

\subsection{Competency management and competency profiles}

A set of intrinsic attributes correlated with the performance in executing specific tasks can be defined as a competency [4, 5]. In organizational context, competencies are context-specific and can be described as the combination of employees' job relevant knowledge, skills and abilities [6] their values, traits, and motivational dispositions [7]. Individual competencies of the employees have a strong organizational relevancy and can be furthermore described as a standardized requirement to properly perform a specific job [8]. The set of specific competences corresponding directly to the employee's working tasks as well as the level of proficiency required, is defined as a competency profile. This can be separated into an is competency profile (describing the actual set of competences of every employee) as well as a to competency profile (depicting an ideal set of competencies for a given work task) [9]. The target- 
performance profile comparison allows a company to identify 1) the customized development of further qualification requirements on the individual level as well as 2) the optimally qualified employees in the context of the staffing process regarding a certain project. Staffing, in particular, requires the best possible matching of the competencies of diverse employees in the context of the requirements and conditions of a certain project and ensures successful functioning of the group.

Purposeful competency management and staffing affect different organizational domains and connect the management of human resources and knowledge with the overall strategic goals of the company. The development of the knowledge resources over time enables a company to gain and sustain competitive advantages. Financial benefits and costs, related to knowledge management are the investigation focus of the knowledge economics [39].

In this manner, competency management contributes to the achievement of the strategic and operative goals and is therefore a crucial factor for the economic success of the enterprise. Particularly, connected to this management topic are human resource management, employee satisfaction as well as an increase in motivation, organizational development, strategic and change management e.g. in the context of the opening up of new markets and introducing products as well as in the context of competency-based project management [10]. The main focus of competency management relies on the purposeful usage of the organizational capabilities on the basis of existing employees' skills. Thus, competency management goes beyond the concepts of qualification and further training and addresses issues such as 1) representation (transparency over actual competences), 2) reflection (defining and development of relevant organizational measures on the basis of actual competences), 3) allocation (placing of employees with relevant competences) and 4) development (adapting competence portfolio considering future capabilities and requirements) [9].

According to [11], the context, in which competencies need to be managed is provided by the process management and process performance management. Furthermore, there is a two way influence between competency management and human resources management as well as knowledge management: 1) competency management on the one hand identifies human resource management and knowledge management needs and 2) on the other hand, human resource management and knowledge management provide artifacts to improve competencies (cf. Figure 1). Intellectual capital management can be seen as the embracing method [12].
Even though the importance of process management in the context of competency management is high, specific modeling methods are missing $[11,6]$. However, existing methods for process based knowledge modeling are well suited to link competency management concepts with process and knowledge management [13, 14, 15]. The practical applicability of those approaches is often aggravated by the fact that they are very detailed and take too many aspects into consideration [11].

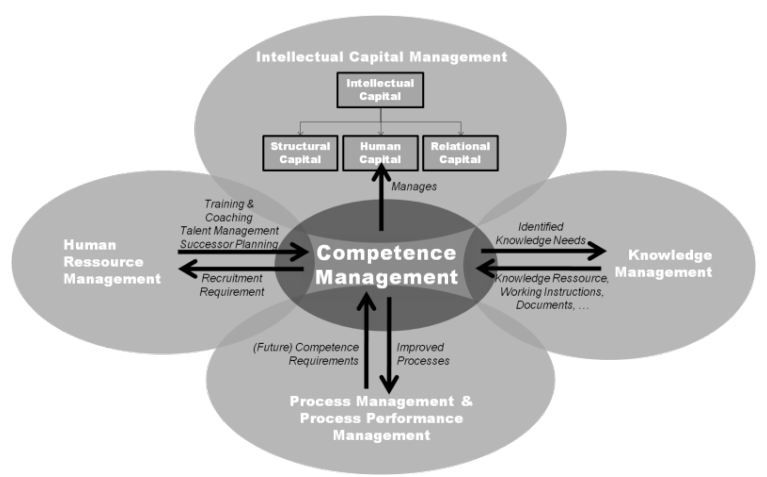

Figure 1. Competence management $(\mathrm{CM})$ in the context of other management disciplines (source Huntringer, Nemetz 2011, p.2)

Against this background, the method presented in this paper focuses explicitly on the identification of $i s$ competencies, the conceptualization and development of to competencies and their comparison with the view to develop qualification requirements on an individual and team/organizational level. Given the time and cost intensity of the comparison process, the use of appropriate methods has a high economic relevance for enterprises.

Within this section, some general specifics of competency management were described with an emphasis on the strategic importance of this management aspect. Furthermore, the importance of process management in the context of competency management, especially regarding the planning of future competency development (s. to competency profiles), as well as the specific relevance of knowledge modeling methods, have been addressed.

Of particular importance is the Industry 4.0 paradigm, addressing one part of the manufacturing process involving actively cyber physical systems. Against this background, the concrete context of the study - its specifics and the resulting main investigation questions will be presented below. 


\subsection{Cyber physical systems}

Cyber physical systems (CPS) describe the integration of computation with physical processes, whereby, embedded computers and networks monitor and control the physical processes and affect each other $[16,17]$. Furthermore, through new modalities such as interfaces, sensors, and actuators CPS are able to interact with humans and actively influence the environment [18]. System operations are monitored, coordinated, controlled and integrated by a computing and communication core [19], where the human factor of integration is no longer mandatory [20].

After (1) mechanization of the manufacturing processes, (2) mass production based on the division of labor and available electricity, and the (3) implementation and usage of electronics and information technology to achieve more automation of manufacturing operations, Industry 4.0 is the fourth industrial revolution, which comprises the integration of interconnected systems and the Internet of Things in manufacturing. It was designated as a German Federal Government's High-Tech Strategy. On the other hand, the US government introduced the term cyber-physical systems, which has been declared as a national research priority of the United States [21].

The main Industry 4.0 -specifics to be pointed out are: 1) The ability of technical "actors" within the manufacturing context to act as knowledge carriers and decision makers. This is a completely new view in knowledge management research, hitherto viewing the human individual as the sole knowing process actor. 2) The high dynamic of changes of processes, tasks, and technology as well as the visionary character of the approach. 3) The enormous demand on competency development and alignment.

\subsection{Human employees and their competencies as a critical Industry 4.0 success factor}

For enterprises in all sectors and sizes, Industry 4.0 creates considerable opportunities, which simultaneously require, amongst other, employee training and further education in the production environment. Technical actors in the context of the factory of the future can be controlled and their functions adjusted to the new working conditions. In contrast, the human ability to change is influenced by individual competencies and qualifications.

In spite of all the technological progress and the resulting changes, human employees remain the decisive critical factor for the economic success of enterprises. In particular, the employees on the shop floor must accept these transformations and adapt to new roles, technologies and tasks. Therefore, working conditions must facilitate employees' flexibility as well as foster learning processes and creativity. This includes a sound work structure, which must be designed in order to fulfill the framework conditions for supporting the acceptance and performance capability as well as employee versatility. The creation of these working conditions within the metamorphosis context of enterprises is both extremely cost and time intensive as well as linked to various uncertainties and risks. Thus, the development of appropriate methods and procedures is of particular economic importance for two reasons: 1) to assure a smooth and prompt change process flow and the consideration of all existing relevant data and information; 2) to increase the motivation and acceptance of the employees by involving them actively in the change process.

\section{Main investigation questions and research design}

Against the backdrop of the technological changes and the necessity to take into account both currently existing and future oriented employee roles and process phase allocation, the following questions have been pointed out as important in the context of the applied research presented in this paper.

1) What are the chief sources of information regarding the to competency and is competency profiles generally as well as specifically for each company?

2) How can the information gained from these sources be used in order to define enterprise specific to competency profiles?

Through the concrete case study examples of factories currently undergoing transformation in the context of Industry 4.0, these questions have been addressed in order to develop a practice-oriented resource saving method for structuring and assisting the competency development process. What the case studies' enterprises have in common is the need and requirement to transform existing manufacturing processes and departments according to the vision of the factory of the future. Transformation as a goal includes many more challenges than the creation of something new. It requires a complete overview of the current situation and clarity regarding the future development status.

Starting points of this investigation have been 1) the current process structures, existing roles and activity types, competencies and relationships between the process members in the above mentioned application contexts, as well as 2) the impact of the 
Industry 4.0 paradigm on the working conditions, the required process modification and the competency management related effects.

The research began with an extensive literature review on the topics of competency, knowledge, change and process management. The merger of the different theoretical disciplines as well as the encounter between theory and practice has been recognized as the biggest challenge within the project.

Given the project structure and aims, the research work has been designed as an action research study. The exploratory character of the empirical investigation on the one hand and the shared interest of researchers and practitioners on the other hand let action research being well-suited to the collaborative research approach.

"Action research simultaneously assists in practical problem-solving and expands scientific knowledge, as well as enhances the competencies of the respective actors, being performed collaboratively in an immediate situation using data feedback in a cyclical process aiming at an increased understanding of a given social situation, primarily applicable for the understanding of change processes in social systems and undertaken within a mutually acceptable ethical framework" [22].

The close collaboration between the research team and the partner organizations allows the verification of the findings gained from the literature review and the theoretical analysis by comparing them with real situations and challenges in organizational practice. Indepth interviews, document analysis, and workshops were conducted for gathering relevant data for the theory and reality comparison.

\subsection{The use and usefulness of Modelangelo}

Although knowledge as an organizational resource is highly relevant for achieving strategic and operative aims, knowledge modeling is the least pronounced compared to other modeling methods and only a few appropriate standards and tools exist. The advantages of knowledge modeling particularly lie in the visualization and analysis of knowledge, knowledge carriers and consumers as well as of knowledge flows and conversions. One suitable modeling method that addresses all these aspects by linking different views is the Knowledge Modeling and Description Language (KMDL) [23, 24]. In a comparison [25] of modeling methods, it was identified as the most suitable for knowledge modeling. Amongst others, this modeling language allows in the context of organizational knowledge management the important differentiation between tacit knowledge (anchored in the minds of employees) and explicit knowledge (equated with information and available in the form of e.g. strategic plans, standard operating procedures, business process models, software structure, data models).

The reference KMDL-software tool is called Modelangelo [26]. The desktop application Modelangelo is a pure Java8 application and solely requires the installation of Java 8 runtime. Modelangelo loads the KMDL-Models into a relational Database, which serves as a temporary data repository during runtime and as a basis for running SQL queries for analysis purposes.

Beside the modeling and analysis aspects, Modelangelo has interfaces to social network platforms and is able to integrate competence information (knowledge, skills and experience in different areas) as well as an overview regarding the existing endorsements (expert skills that have been confirmed by others). Modelangelo has an adapter to LinkedIn, which is based on the Apache Camel framework (Figure 2). It can be used as a desktop application as well as for iOS and in a mobile prototype version for Android. Thus, it allows for Mobile Knowledge Modeling (Mobile Modeling) which has two major advantages: 1) From the managerial point of view, the instant access to knowledge events; 2) From the process owner point of view, a direct, time and location independent notification of relevant operational events. Mobile devices are furthermore appropriate applications within a manufacturing context. Using mobile devices, thoughts, ideas and knowledge, which arise ad hoc within process flows, can be both captured and dispatched to information systems almost losslessly. Required metadata can be retrieved and combined directly. This addresses the requirements for temporal and spatial independence to capture businessrelevant data and return them back to the business information systems in a structured fashion, which is especially important within the context Industry 4.0.

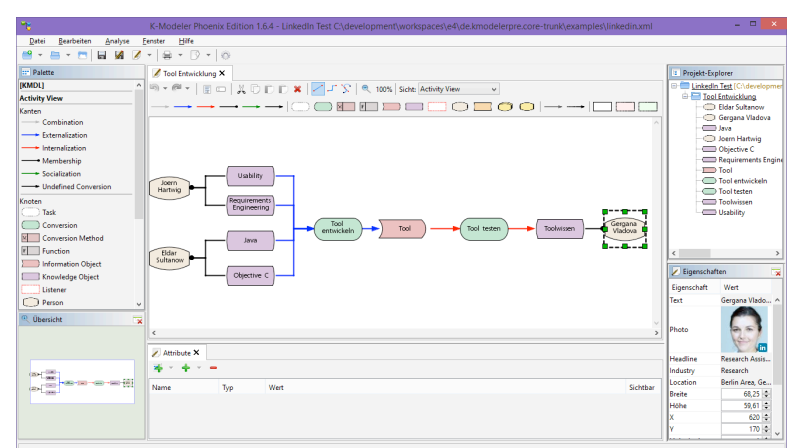

Figure 2. Modelangelo - knowledge modeling example including LinkedIn reference information

For the purpose of the project, the development of the competency modeling and analysis method as well 
as the KMDL-extension for an automated comparison of is-and to competencies was conducted. The goal of the method and tool is to enable this comparison in a resource-saving manner.

\section{Description of the method and application example}

In the main, the method provides an overview of existing and required skills at both the process and the individual employee's level. The aim is to provide enterprises with a concept and tool allowing for linking the competency management process, knowledge and human resources management in order to take into consideration as many aspects as possible and create appropriate employee qualification and training concepts.

Before beginning with the description of the single methodological procedure, some framework conditions need to be clarified:

Organizational requirements: In order to apply the method, the organization should first appoint a responsible team, including managers, manufacturing team leaders, employees, and the human resources department.

Technical requirements: The installation and use of the modeling tool Modelangelo is highly recommended even if parts of the analysis method can be applied on their own.

Figure 3 visualizes the steps of the methodological procedure with references to the use of the modeling tool Modelangelo.

Focusing on replying to the questions mentioned in section 3, the authors refrain from explaining the procedural model in detail. The methodology shows similarities to the usual project management flow (compare Figure 3). In the following, only the results regarding the main questions will be discussed in context of the procedure model.

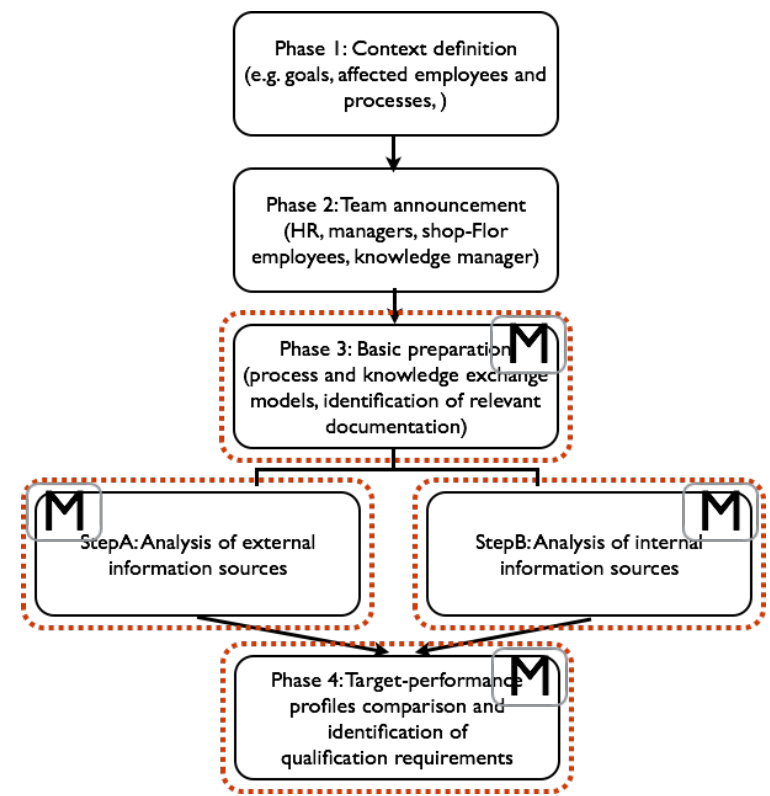

Figure 3. Procedure model and Modelangelo points of intersection (marked with ,M“)

\subsection{Important results within Phase 3, Steps A and $B$}

As a result of 1) the literature review on the topics of competency management and Industry 4.0, as well as of 2) the workshops and interviews with managers, HR managers and employees, and 3) the documentation analysis, different competency profiles sources have been identified. Depending on the type of competency, these sources are summarized in Table 1 (to competencies) and Table 2 (is competencies).

Table 1. To competencies sources

\begin{tabular}{|l|l|l|}
\hline $\begin{array}{l}\text { External } \\
\text { Source }\end{array}$ & $\begin{array}{l}\text { To competencies } \\
\text { papers working } \\
\text { recommendations } \\
\text { on the topics } \\
\text { factory of the } \\
\text { future, CPS and } \\
\text { Industry 4.0 }\end{array}$ & $\begin{array}{l}\text { Already } \\
\text { implemented in } \\
\text { Modelangelo } \\
\text { (requirement } \\
\text { template) }\end{array}$ \\
\hline Internal & $\begin{array}{l}\text { White papers, job } \\
\text { Source }\end{array}$ & $\begin{array}{l}\text { Industry } \\
\text { project } \\
\text { documentation, } \\
\text { competency } \\
\text { requirements, } \\
\text { created by the } \\
\text { team on the basis } \\
\text { of the enterprise } \\
\text { specific vision of } \\
\text { the factory of the }\end{array}$ \\
\hline
\end{tabular}




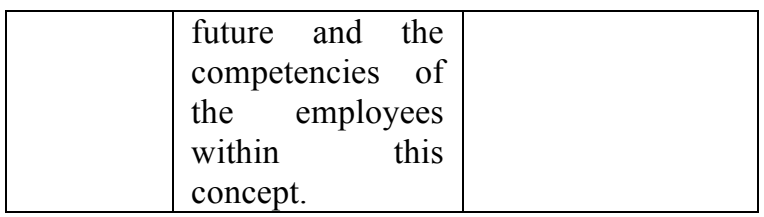

* These competencies, that have been summarized as a result of the literature analysis and can be loaded directly and used in Modelangelo as a requirement template, are exemplified in Figure 4.

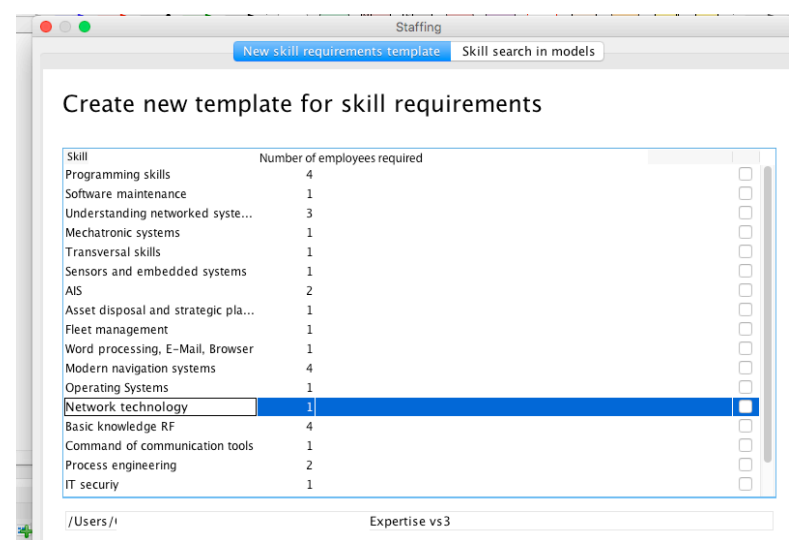

Figure 4. Skill requirements template

The existing list can be modified by the enterprise: skills can be included or deleted, and the required number of employees with this skill can be individually determined.

Table 2. Is competencies sources

\begin{tabular}{|l|l|l|}
\hline & Is competencies & Identification by \\
\hline $\begin{array}{l}\text { External } \\
\text { Source }\end{array}$ & $\begin{array}{l}\text { Application } \\
\text { documents of new } \\
\text { employees }\end{array}$ & Industry 4.0-team \\
\hline $\begin{array}{l}\text { Internal } \\
\text { Source }\end{array}$ & $\begin{array}{l}\text { Personal files and } \\
\text { training history }\end{array}$ & $\begin{array}{l}\text { Industry 4.0-team } \\
\text { (especially HR) }\end{array}$ \\
& $\begin{array}{l}\text { Process and } \\
\text { knowledge } \\
\text { modeling } \\
\text { (competency profile } \\
\text { models, KMDL- } \\
\text { activity models **) }\end{array}$ & \\
\hline
\end{tabular}

**The activity view models represent information and knowledge flows as well as knowledge conversions, which occur during and in between business processes [13]. They should be identified and modeled at the outset of the project and can be modified on demand. Figure 5 shows an example of a part of such a model. The competency profile models represent a selection of all knowledge objects associated with one person (employee).

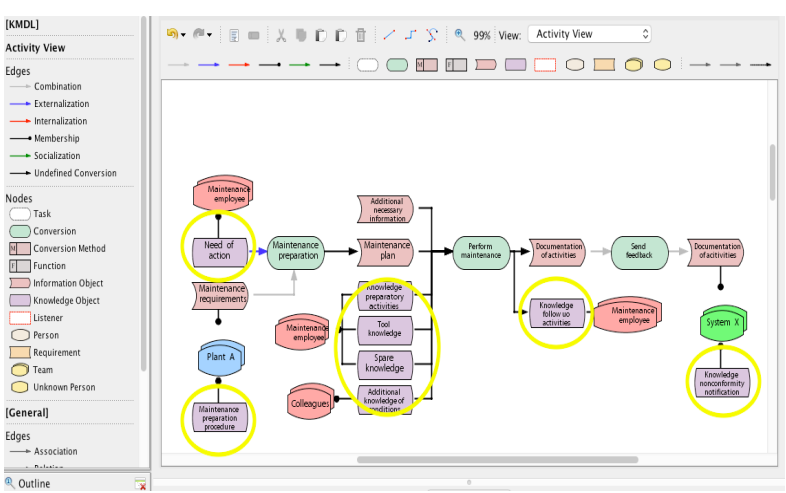

Figure 5. Modelangelo KMDL activity view example: Industry 4.0-context of knowledge and information exchange (knowledge objects are circled in yellow)

\subsection{Important results within Phase 4}

Using the information gained from the internal and external sources, as a final analysis step, a targetperformance profile comparison can be carried out (Figure 6) in order to define the to competencies and respectively the employees with competency development needs. In order to do this, Modelangelo allows for the comparison of the requirement templates with the KMDL models as well as with the existing employee competency profiles. The tool represents the results as a list of all employees acting within a given model repository. Employees with the required competencies are pointed out.

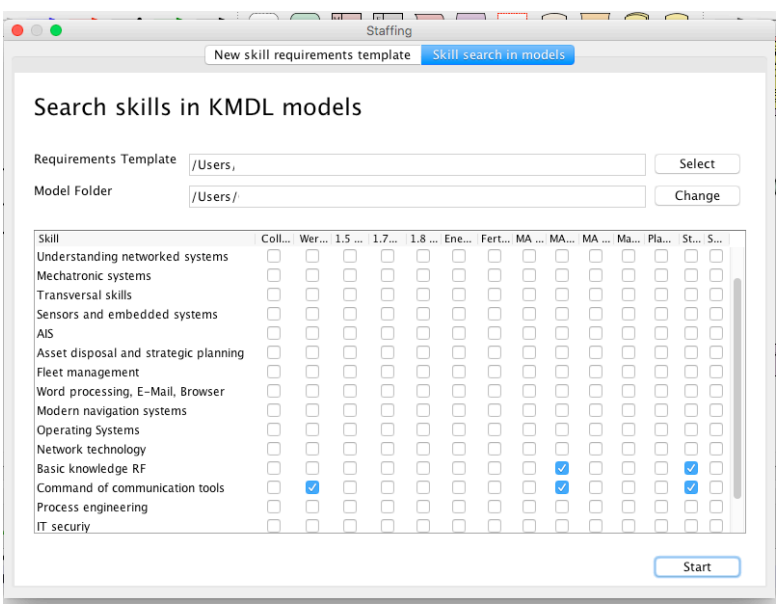

Figure 6. Skill search in models 


\subsection{Results in form of general recommendations}

On the basis of the information collected from internal and external sources, implications regarding the answer to the second question can be understood. Compared with the first question, these implications should be defined in a much more company specific way. However, the topic of this paper pertains only to curtain general recommendations:

Given that the competency definition has a vision and future oriented context, the enterprise should firstly orientate itself according to the recommendations given by the governance or by Industry 4.0 responsible public authorities. However, the main responsibility of the internal Industry 4.0 team relies on the adaption of these competency recommendations drawn from the individual enterprise circumstances. In order to do this, a review and modification of the predefined competency requirement templates (s. Figure 5) as well as the creation of completely new templates and the matching of the templates with the activity view models can be used.

One additional benefit of the models' analysis is the visualization of the knowledge and information exchange with technical actors. On the basis of these models, the enterprise can easily identify the employees communicating directly with technical entities and develop specific qualification requirements in order to improve not only their expertise, but also their motivation, acceptance and vision understanding. Furthermore, the localization of the knowledge objects belonging to technical entities allows for the creation of competency profiles also for technical "employees" and the establishing of new possibilities for staffing and competence management.

\section{Conclusions}

Competency management is a crucial success factor for organizations in the area of tension between knowledge management, human resources management, and process management and has to be considered from a knowledge economical perspective. Especially in manufacturing environments, work organization concepts such as job rotation represent a mandatory part of employee qualification, which also enable hedging against staff shortages. However, the systematic capturing of employee respective competencies and their analysis is not sufficiently provided yet. Thus, the paper presents a procedural method and a software tool for the efficient comparison of is competencies and to competencies.
Therein lies the contribution to the field of this paper. Firstly, the procedural method, which was developed by means of the application contexts of the three corporations, contributes mainly to the research community, however it is intended to be applied by practice, too. Secondly, the developed software tool, which can be used for the mentioned comparison of the competencies, primary addresses the practice community.

The procedural method structures and assists the process of qualification development. The usage of such assistance systems is a strategic decision. Through the application, enterprises will be enabled to capture and identify requirements in an automated manner. Additionally, employees will be enabled to transfer qualification requirements directly to the corresponding qualification authority by the aid of the tool.

The action research approach, which is the underlying methodological basis of this study, obviously has limitations. Action research enables the development of practical solutions, but it is notably lacking in terms of a theoretical basis, and thereby, of making a profound theoretical contribution.

The generalizability of the developed results is also in question. A possible solution approach for fostering the theoretical basis is to integrate a complementary research method, which is also capable of extending the generalizability of this study.

Further research addresses the extension of application contexts to other sectors and, within this, the extension of the competency database. Additionally, the implementation in the application contexts information technology infrastructure is envisaged.

\section{Acknowledgements}

This research and development project is funded by the German Federal Ministry of Education and Research (BMBF) within the Framework Concept "Research for Tomorrows Production (funding number 02PJ4040 ff) and managed by the Project Management Agency Karlsruhe (PTKA). The authors are responsible for the contents of this publication.

The authors would like to thank the unknown reviewers for their constructive feedback, which immensely helped to improve this contribution.

\section{References}

[1] R. Müller, and R. Turner, "Leadership competency profiles of successful project managers", International Journal of Project Management 28.5 2010, pp. 437-448. 
[2] M.A. Vaz, S.N. Brandao, W.N. Silva, and J.M. Souza, "A Competence Management Model of a Energy Company", In: IADIS International Conference e-Society, Porto, Portugal, 2010 .

[3] H.J. Pongratz, and G. Voß., "From employee to 'entreployee': Towards a 'self-entrepreneurial'work force?", Concepts and Transformation 8.3, 2003, pp 239-254.

[4] L.M. Spencer, and S.M. Spencer, "Competence at Work. Models for Superior Performance“, Wiley, New York, 1992.

[5] R.E. Boyatzis, "The Competent Manager: A Model for Effective Performance", Wiley, New York, 1982.

[6] G. Berio, and M. Harzallah, "Knowledge management for competence management" Journal of Universal Knowledge Management 1/2005, pp. 21-28.

[7] D.C. McClelland, "Testing for competence rather than for" intelligence", American psychologist 28.1, 1973, pp. 114.

[8] W.R.J. Baets, and G. van der Linden, "Virtual Corporate Universities: A Matrix of Knowledge and Learning for the New Digital Dawn", Kluwer Academic, Norwell, 2003.

[9] K. North, and K. Reinhardt, "Kompetenzmanagement in der Praxis - Mitarbeiterkompetenzen systematisch identifizieren, nutzen und entwickeln“, Gabler, 2005.

[10] K. Reinhardt, "Studie Betriebliches Kompetenzmanagement - Chancen und Herausforderungen für die Praxis", Fraunhofer IFF. Magdeburg, 2004.

[11] S. Hintringer, and M. Nemetz, "Process Driven Competence Management: A Case Study at Hilti Corporation", 6th Conference on Professional Knowledge Management: From Knowledge to Action, February 21-23, 2011 in Innsbruck, Austria.

[12] M. Nemetz, "Intellectual Capital Management and Reporting -Achieving Comparability and Expressiveness by Applying the Meta-Modeling Approach", Suedwestdeutscher Verlag für Hochschulschriften, 2009.

[13] N. Gronau, and J. Fröming, "KMDL® Eine semiformale Beschreibungssprache zur Modellierung von Wissenskonversionen", In: Wirtschaftsinformatik, Vol 48, 2006, pp. 349-360.

[14] P. Heisig, "The GPO-WM® Method for the Integration of Knowledge Management into Business Processes“, In: Proceedings of I-Know '06, Graz, Austria, 2006.

[15] R. Woitsch, and D. Karagiannis, "Process oriented knowledge management: a service based approach", In: Journal of Universal Computer Science 11, 4/2005, pp. 565588.
[16] E.A. Lee, "Cyber-physical systems - are computing foundations adequate", Position Paper for NSF Workshop On Cyber-Physical Systems:Research Motivation, Techniques and Roadmap, Citeseer, 2006.

[17] E.A. Lee, "Cyber physical systems: Design challenges. In: Object Oriented Real-Time Distributed Computing“, (ISORC), 2008 11th IEEE International Symposium on IEEE, 2008, pp 363-369.

[18] R. Baheti, and H. Gill, "Cyber-physical systems", In: The impact of control technology 12/2011, pp. 161-166.

[19] R.R. Rajkumar, I. Lee, L. Sha, and J. Stankovic, "Cyberphysical systems: the next computing revolution", In: Proceedings of the 47th Design Automation Conference ACM, 2010, pp. 731-736.

[20] G. Schirner, D. Erdogmus, K. Chowdhury, and T. Padir, "The future of human-in-the-loop cyber-physical systems", In: Computer 1/2013, pp. 36-45.

[21] H. Gill, "From vision to reality: cyber-physical systems", In: Presentation, HCSS National Workshop on New Research Directions for High Confidence Transportation CPS: Automotive, Aviation and Rail, 2008.

[22] M. Hult, and S.A. Lennung, "Towards a Definition of Action Research: A Note and Bibliography." Journal of Management Studies, Vol. 17, 2, 1980, pp. 241-250.

[23] N. Gronau (ed.), "Modeling and Analyzing knowledge intensive business processes with KMDL: Comprehensive insights into theory and practice", GITO, 2012.

[24] N. Gronau, and C. Maasdorp (eds.), "Modeling of Organizational Knowledge and Information", GITO, 2016.

[25] E. Sultanow, X. Zhou, N. Gronau, and S. Cox, "Modeling of Processes, Systems and Knowledge: A MultiDimensional Comparison of 13 Chosen Methods", International Review on Computers and Software 7.6/2012, pp. 3309-3319.

[26] http://www.kmdl.de/en/node/46, retrieved 05.06.2016.

[27] H. Kock, A. Gill, and Per Erik Ellström, "Why do small enterprises participate in a programme for competence development?" Journal of Workplace Learning, Vol.20 3/2008, pp. 181-194.

[28] E. Bell, S. Taylor, and R. Thorpe, "Organizational differentiation through badging: Investors in People and the value of sign", Journal of Management Studies, Vol. 39 8/2002,, pp. 1071-1086.

[29] M, A.Zangiski,, E. P. de Lima, and S. E. Gouvea da Costa, "Organizational competence building and development: Contributions to operations management." International Journal of Production Economics 144, 1/2013, pp. 76-89. 
[30] R. K. Potnuru, and C. K. Sahoo, "HRD interventions, employee competencies and organizational effectiveness: an empirical study" European Journal of Training and Development $40,5 / 2016$.

[31] C. Brockmann, and N. Roztocki, "Knowledge Economics Minitrack Introduction" In: 46th Hawaii Conference for System Sciences (HICSS), Wailea, USA, 2013.

[32] C. Brockmann, and N. Roztocki, "The Evolution of Knowledge Economics through the Course of Time: An Analysis of the Hawaii International Conference on System Sciences (HICSS) Minitrack." In: 47th Hawaii International Conference on System Sciences, pp. 3471-3477. IEEE, 2014.

[33] N. J. Foss, and C. Knudsen, "Towards a competence theory of the firm" Vol. 2. Routledge, 2013.

[34] D. Ulrich, "Human resource champions: The next agenda for adding value and delivering results" Harvard Business Press, 2013.

[35] B. Becker, and B. Gerhart, "The impact of human resource management on organizational performance: Progress and prospects." Academy of management journal 39, 4/1996, pp. 779-801.
[36] M. Homer, "Skills and competency management." Industrial and Commercial training 33, 2/2001, pp. 59-62.

[37] E. Appelbaum, "The impact of new forms of work organization on workers." Work and Employment in the High Performance Workplace 120/2013.

[38] M. Rosemann, and J. vom Brocke, "The six core elements of business process management." In Handbook on Business Process Management 1, pp. 105-122. Springer Berlin Heidelberg, 2015.

[39] C. Brockmann, and N. Roztocki, "Topics on Knowledge Management: An Empirical Insight into Articles Published in the International Journal of Knowledge Management": In 48th Hawaii International Conference on System Sciences, pp. 3834-3840. IEEE, 2015.

[40] J. Kowal, and N. Roztocki, "Information and communication technology management for global competitiveness and economic growth in emerging economies." The Electronic Journal of Information Systems in Developing Countries 57/2013.

[41] C. Brockmann, "An approach to design the business model of an ERP vendor" GITO, 2014. 